NBER WORKING PAPER SERIES

GOVERNMENT AND HEALTH OUTCOMES

Michael Grossman

Working Paper No. 780

NATIONAL BUREAU OF ECONOMIC RESEARCH

1050 Massachus etts Av enue

Cambridge MA 02138

October 1981

The research reported here is part of the NBER's research program in Health Economics. Any opinions expressed are those of the author and not those of the National Bureau of Economic Res earch. 


\begin{abstract}
In this paper, I summarize the results of empirical studies in the areas of schooling and health, public programs and infant mortality, and government regulation of teenage smoking. My review is selective and is based on my own research. It is neutral with respect to the question of whether the government should pursue policies to improve the health of its citizens. But it calls attention to the consequences with respect to health of alternative decisions by policy makers.
\end{abstract}

Michael Grossman

Department of Economics

City University of New York Graduate School 33 West 42 nd Street New York, New York 10036

(212) 790-4426

National Bureau of Economic Research 269 Mercer Street, 8th Floor New York, New York 10003

(212) 598-3321 
GOVERNMENT AND HEALTH OUTCOMES

by Michael Grossman*

I have been engaged in research in health economics at the National Bureau of Economic Research for more than a decade. A common theme in much of $\mathrm{my}$ research is that health is the output of a multivariate production process in which medical care is simply one of many inputs. This distinction between health and medical care is a useful point of departure in a discussion of government and health outcomes because it underscores that actual and potential government policies with respect to a variety of nonmedical inputs can have important impacts on health outcomes. Indeed, a good deal of evidence suggests that these inputs are more important determinants of health in the United States than medical care. Consequently, the way in which the government affects the health of its citizens may have more to do with its impacts on nonmedical than on medical inputs.

In this paper, I sumarize the results of empirical studies in the areas of schooling and health, public programs and infant mortality, and government regulation of teenage smoking. My review is selective and is based on my own research. It is neutral with respect to the question of whether the government should pursue policies to improve the health of its citizens. But it calls attention to the consequences with respect to health of alternative decisions by policy makers. 


\section{Schooling and Health}

A number of studies in the United States indicate that among socioeconomic varlables years of schooling completed is probably the most important correlate of good health in adult populations. This finding emerges whether health levels are measured by mortality rates, morbidity rates, or self-evaluation of health status, and whether the units of observation are individuals or groups. The relationship is usually statistically significant at levels of confidence of .05 or better in both simple and partial correlations. Moreover, a significant and large schooling effect is observed with income held constant.

Clearly, schooling is a variable within the purview of public policy. Its average level is determined in part by such Federal prorams as elementary and secondary school aid, grants to colleges and to iw-income students, and guaranteed and subsidized student loans. If the correlation between schooling and health reflects causality from the former to the latter, health levels may grow more slowly than otherwise and may even decline as a result of the recently enacted budget cut-backs in Federal aid to education by the Reagan Administration. Correlation, however, is not synonymous with causality. The direction of causality may run from better health to more schooling because healthier students may be more efficient producers of additions to the stock of knowledge, or human capital, via formal schooling and because current and past health are likely to be positively related. Alternatively, no causal relationship need be implied by the correlation between schooling and health. Instead, differences in one or more 
"third variables," such as physical and mental ability and parental characteristics, may affect both health and schooling in the same direction. I have subjected the alternative explanations of the observed positive correlation between schooling and health to empirical testing and have concluded that schooling has a significant and large causal impact on the current self-rated health of middle-aged white male adults in the NBER-Thorndike sample. The estimated schooling effect in my study controls for health in high school, parents' schooling, scores on physical and mental tests taken by the men when they were in their early twenties, current hourly wage rate, property income, and job satisfaction. My finding is particularly notable because all of the men graduated from high school. Hence, it suggests that the favorable impact of schooling on health persists even at high levels of schooling.

Additional evidence that schooling causes health is contained in research by Linda Edwards, Robert Shakotko, and me on the determinants of child and adolescent health. We study child and adolescent health in the context of the nature-nurture controversy. Our research uses data from Cycle II of the U.S. Health Examination Survey (children aged 6 through 11 years in the period 1963 through 1965), Cycle III of the liealth Examination Survey (adolescents aged 12 through 17 years in the period 1966 through 1970), and the panel of individuals (one-third of the full (ycle III sample) who were examined in both cycles.

We find that the home environment in general and mother's schooling in particular play an extremely important role in the determination of child and adolescent health. It is not surprising to find that a 
child's home environment has a positive impact on his health with no other variables held constant. Moreover, it is difficult to sort out the effect of nature from that of nurture because it is difficult to measure a child's genetic endowment and because genetic differences may induce environmental changes. Nevertheless, we have accumulated a number of suggestive pleces of evidence on the true importance of the home environment. With birth weight, mother's age at birth, congenital abnormalities, other proxies for genetic endowment, and family income held constant, parents' schooling has positive and statistically significant effects on many measures of health in childhood and adolescence. Children and teenagers of more educated mothers have better oral health, are less likely to be obese, and less likely to lisye anemia than children of less educated mothers. Father's schooling plays a much less important role in the determination of oral beaith, obesity, and anemia than mother's schooling. The latter findings are important because equal effects would be expected if the schooling variables were simply proxies for unmeasured genetic endowments. On the other hand, if the effect of schooling is primarily environmental, we would expect the impact of mother's schooling to be larger because she is the family member most concerned with children's health care.

Several additional pieces of evidence underline the robustness of the above finding. When oral health is examined in a longitudinal context, mother's schooling dominates father's schooling in the determination of the periodontal index in adolescence, with the periodontal 
index in childhood held constant. Similar comments apply to the effect of mother's schooling on school absence due to 1 llness in adolescence (with school absence due to illness in childhood held constant) and to the effect of mother's schooling on obesity in adolescence (with obesity in childhood held constant).

\section{Public Programs and Infant Mortality}

From 1964 to 1977, the infant mortality rate in the United states declined at an annually compounded rate of 4.4 percent per year. This was an extremely rapid rate of decline compared to the figure of 0.6 percent per year from 1955 to 1964. The reduction in mortality proceeded at an even faster pace in the 1970s than in the late 1960s 15.2 pescent per year from 1971 to 1977 versus 3.8 percent per year from 1964 to 1971). The period from 1964 to 1977 witnessed the introduction of Medicaid, maternal and infant care projects, Federally subsidized family planning services for low-income women, and the legalization of abortion. Steven Jacobowitz and I recently have completed a study in which we estimate the relative impacts of these public policies and programs on infant mortality in a multivariate context.

We focus on the neonatal mortality rate (deaths of infants within the first 27 days of life per thousand live births). This rate is generally about three times as high as the postneonatal mortality rate (deaths of infants between the ages of 28 and 364 days per thousand live births), making the neonatal mortality rate the most important contributor to infant mortality. Moreover, the policy variables at 
1ssue are more relevant to neonatal mortality than to postneonatal mortallty.

The methodology of our study involves a cross-sectional regression analyses of variations in race-specific neonatal mortality rates among large countles of the United States in 1971. Independent variables in the regressions include physiclans per capita, the percentage of women in childbearing ages who had at least a high school education, the percentage of the population in poverty, and policy measures pertaining to Medicaid coverage of prenatal and perinatal care services, maternal and infant care projects, the use of organized family planning clinics by low-income women in childbearing ages, and abortion reform. This procedure capitalizes on variations in the programs at issue among counties at a moment in time, while mitigating the multicollinearity problems that almost certainly would arise in a time-series analysis for the U.S. as a whole. To examine the relative contributions of schooling, poverty, physician availability, and the public programs to the recent U.S. neonatal experience, we apply the regression coefficients to trends in the exogenous variables between 1964 and 1977. In that period the white neonatal mortality rate declined by 7.5 deaths per thousand live births, and the nonwhite neonatal mortality rate declined by 11.8 deaths per thousand live births. The regressions explain approximately 35 percent of the white decline and 41 percent of the nonwhite decline.

The increase in the legal abortion rate is the single most important factor in reductions in both race-specific death rates. Not only 
does the growth in abortion dominate the other program measures, but it also dominates trends in schooling, poverty, and physician availability. For the entire 1964-77 period, the reduction in the white neonatal mortality rate due to abortion amounts to approximately 1.6 deaths per thousand live births or 21 percent of the observed decline. The comparable figure for nonwhites is 2.5 deaths per thousand live births, which also amounts to 21 percent of the observed decline. When the subperiods of 1964-71 and 1971-77 are examined separately, abortion makes the largest contribution except for nonwhites in the 1964-71 period. Here it ranks second to the impact of the rise in the use of organized family planning services by low-income women. The extremely large expansion in the abortion rate in the latter period (1971-77) Erovides a cogent explanation of the acceleration in the percentage rates of decline in both race-specific mortality rates and the acceleration in the absolute rate of change for whites.

These results are relevant to current U.S. policy debates with respect to the financing of abortions and family planning services under Medicaid and with respect to attempts to outlaw abortion except when it is necessary to preserve a pregnant woman's life. Taken at face value, the most striking implication of our study pertains to a ban on abortions. The current U.S. abortion rate is 400 abortions per thousand live births, while the rate in 1969 was 4 abortions per thousand live births. If a ban reduced the rate to its 1969 level, our regressions predict that the nonwhite neonatal mortality rate would rise by approximately 2.8 per thousand live births or by 19 
percent above 1ts 1977 level. The white neonatal mortallty rate would rise by approximately 1.8 deaths per thousand live births or by 21 percent above its 1977 level. Yet these estimates must be regarded with caution because they assume that all other factors would remain the same if a ban were enacted. In particular, they overstate the impact of an abortion ban to the extent that more conventional methods of birth control would be substituted for abortions.

III. Government Regulation of Teenage Smoking

Since the issuance of the first Surgeon General's Report on Smoking and Health in 1964, the Federal government has been involved in a sporadic campaign to discourage cigarette smoking. This campaign has consisted primarily of policies designed to increase pubjic knowledge of the harmful effects of cigarette smoking and to restrict advertising by cigarette manufacturers. The major elements of this campaign have been the Fairness Doctrine of the Federal Communications Commission, which resulted in the airing of anti-smoking messages on radio and television from July 1, 1967 to January 1, 1971, and the Public Health Cigarette Smoking Act of 1970, which banned prosmoking cigarette advertising on radio and television after January 1 , 1971. The ban greatly reduced the airing of anti-smoking messages, relegating them to the same status as other public service advertising. This has caused a number of observers to question the substitution of the broadcast advertising ban for the active anti-smoking campaign mounted under the Fairness Doctrine. 
Eugene Lewit, Douglas Coate, and I recently have completed a study which contains the first set of estimates of the impact of the Fairness Doctrine and advertising ban policies on the demand for cigarettes by teenagers in the United states. In addition, we examine the extent to which an increase in the Federal excise tax on cigarettes would reduce teenage smoking. Excise tax changes are reflected in cigarette prices and comprise an additional public policy that influences cigarette demand. We focus on teenagers because cigarette smoking is, in part, an habitual behavior that begins early in life. Therefore, changes in teenage smoking behavior in response to government regulatory actions can have a substantial and sustained impact on aggregate smoking in the long run. Moreover, age at onset of smoking is negatively correlated itis the amount smoked and the incidence of negative health effects. Trends in smoking participation rates of teenagers underscore another reason for studying this group in the context of the antismoking campaign. Supporters of the advertising ban have pointed to the increase in teenage smoking rates between 1968 and 1970 as evidence that, whatever the impact of the Fairness Doctrine on aggregate cigarette consumption, the doctrine was not effective in the case of tsenagers. Ignored in this argument is the important point that the Falrness Doctrine went into effect on July 1, 1967. Therefore, smoking rates in 1968 pertain to rates in the second half of the first year and first half of the second year of the doctrine. Thus, trends between 1968 and 1970 do not allow one to compare teenage smoking in the period before the Fairness Doctrine to smoking during the doctrine. 
Our empirical research is based on Cycle III of the Health ExamInation Survey. Since some of the teenagers in this sample were interviewed before the period of the Fairness Doctrine while others were interviewed during the period of the doctrine, we are able to present the first multivariate evaluation of the Fairness Doctrine on teenage smoking. In addition, since some of our estimated equations include the number of pro- and anti-smoking messages seen by each youth, we are able to make predictions about the potential impacts of the advertising ban. We also present the first estimates of the responsiveness of smoking by teenagers to variations in the price of cigarettes. This is possible because of cross-sectional differences in the price of cigarettes, primarily due to differences in state excise tax rates. We find that teenage price elasticities of demand for cigarettes ros substantial and much larger than the corresponding adult price elasticities. The teenage smoking participation elasticity equals -1.2, and the quantity smoked elasticity equals -1.4. It follows that, If future reductions in youth smoking are desired, an increase in the Federal excise tax is a potent policy to accomplish this goal. The contention of the proponents of the advertising ban that the Faiziness Doctrine falled in the case of teenagers is incorrect. According to our results, the doctrine had a substantial negative impact on teenage smoking participation rates. Extrapolations that as sume no changes in the determinants of teenage smoking except for variables related to the Fairness Doctrine suggest that the advertising ban was no better or worse a policy than the Fairness Doctrine. When, however, we take account of the 6 percent reduction in the relative price 
of clgarettes between 1970 and 1974, which Benfamin Klein, Kevin Murphy, and Lynne Schneider attribute to the advertising ban, we predict an increase in smoking participation of .4 percentage points. This coincides with the observed increase and calls into question the wisdom of the advertising ban, at least in the short run.

\section{Agenda for Future Research}

In lieu of a conclusion, I want to highlight three items on an agenda for future research. In the area of neonatal mortality, I plan to study the determinants of variations in these rates among counties of the U.S. in 1977. This will enable me to address the question: Do the effects that were observed in 1971 differ when data for 1977 are examined? Moreover, Jacobowitz and I were not able to measure the contributions of advances in neonatology to reductions in neonatal mortality. It is true that the state-of-theart in neonatology is fixed in the cross section. But the extent to which state-of-the-art services are delivered to infants is not fixed because of differences in the availability of neonatal intensive care units among counties. Measures of the availability of these units will be included in my new study.

In the area of teenage smoking, Lewit, Coate, and I will assess the long-run impacts of the advertising ban using the National surveys on Drug Abuse conducted in 1971, 1972, 1974, 1976, 1977, and 1979. It is plausible that the possible long-run effects of the ban primarily will be experienced as succeeding cohorts of children are reared without exposure to pro-cigarette advertising on television. In particular, 
as the advertising ban remains in effect, children of the same age will have had less total lifetime exposure to cigarette advertising in each succeeding year. Consequently, we will pay particular attention to interaction effects between age and the duration of the ban as revealed in the $s i x$ recent surveys.

In the area of schooling and health, Victor Fuchs has challenged my conclusion that schooling has a substantial causal impact on health. He argues that the relationship may be due to an omitted third factor: namely, differences in time preference among individuals. Fuchs has attempted to measure time preference in a telephone survey by asking respondents questions in which they choose between a sum of money now and a larger sum in the future. He includes an index of time prefercrec in a multiple regression in which health status is the dependent varlable and schooling is one of the independent variables. To date, Fichs has not been able to demonstrate that the schooling effect is due to time preference, but his results must be regarded as preliminary. In particular, they are based on one small sample of adults in Long Island and on exploratory measures of time preference. In general, I applaud his effort to study the relationship between schooling and health in more detail, and I agree with his contention that the mechanisms through which schooling affects health have not been fully identified. 
FOOTNOTES

"This paper will be presented at an American Economic Association invited session on Government and Health at the Allied Social Science Associations annual meeting, Washington, D.C., December 28-30, 1981. I am indebted to Douglas Coate and Linda Edwards for their comments on an earlier draft. Research summarized in this paper was supported by Grant Numbers 5 POI HS00451 and 1 ROI HS02917 from the National Center for Health Services Research to the National Bureau of Economic Research, by Grant Number DAR-80 14959 from the National Science Foundation to the NBER, and by grants from the Ford Foundation and the Robert Wood Johnson Foundation to the NBER. 
Edwards, Linda N., and Grossman, Michael. "Adolescent Health, Faraily Background, and Preventive Medical Care." In volume III of Research In Human Capital and Development, edited by Ismail Sirageldin, David Salkever, and Alan Sorkin. Greenwich, Connecticut: JAI Press, Inc., forthcoming.

Edwards, Linda N., and Grossman, Michael. "Children's Health and the Family." In Volume II of Advances in Health Economics and Health Services Research, edited by Richard M. Scheffler and Louis F. Rossiter. Greenwich, Connecticut: JAI Press, Inc., 1981.

Fuchs, victor R. "Time Preference and Health: An Exploratory Study." In Economic Aspects of Health, edited by Victor R. Fuchs. Chicago: University of Chicago Press for the National Bureau of Economic Research, 1982.

Grossman, Michael. "The Correlation between Health and Schooling." In Household Production and Consumption, edited by Nestor $\mathbf{E}$. Terleckyj. New York: Columbia University Press for the National Bureau of Economic Research, 1975.

Grossman, Michael, and Jacobowitz, Steven. "Variations in Infant Mortality Rates among Counties of the United States: The Roles of Public Policies and Programs." Demography, 18, No. 4 (November 1981). 


$$
\mathbf{R}-\mathbf{2}
$$

Klein, Benjamin, Murphy, Kevin M.; and Schneider, Lynne. "Government Regulation of Cigarette Health Information." Journal of Law and Economics, 24, No. 3 (December 1981).

Lewit, Eugene M.; Coate, Douglas; and Grossman, Michael. "The Effects of Government Regulation on Teenage Smoking." Journal of Law and Economics, 24, No. 3 (December 1981).

Shakotko, Robert A.; Edwards, Linda N.; and Grossman, Michael. "An Exploration of the Dynamic Relationship between Health and Cognitive Development in Adolescence." In Contributions to Economic Analysis: Health, Economics, and Health Economics, edited by Jaques van der Gaag and Mark Perlman. Amsterdam: North-Holland Publishing Company, 1981. 